\title{
DISCURSIVE PERSONALITY OF THE TRANSLATOR: TRANSLATION COMPETENCIES AND ROLE PORTRAIT ${ }^{1}$
}

\author{
Elina Yu. Novikova \\ Volgograd State University, Volgograd, Russian Federation
}

\begin{abstract}
Professional and discursive peculiarities of translation are considered in this article. Nowadays the personality of the translator includes his/her various roles constituting the translator's role portrait and represents an exclusive discursive personality. Translation historically has given translators the opportunity to develop an unprecedented number of competencies and this number keeps getting even bigger at the modern stage of the global social development. The author's attention is focused on various approaches to defining the role status of the translator. The work of a professional translator is multi-faceted as translational action takes place within various discursive practices which variously shape the discursive personality of the translator, his/her professional portrait and communicative behaviour. It is evident that the translator performs communicative action within various discourses, i.e. he/she acquires new discursive features as a result of every single act of communication and thus represents a complicated multi- and interdiscursive phenomenon. A review and analysis of various translational roles are presented in this article. The research has shown that the translator acts as an intercultural communication expert, an intermediary between worlds and cultures, a language consultant, a specialist in the field of another culture, a co-author, an actor, a playwright, a cultural mediator, a designer, a partner, an observer, a nomad, i.e. homo universalis, an exclusive, multifunctional, social and communicative discursive personality.

Key words: translator, discursive personality, role portrait, professional competence, tourism discourse.

Citation. Novikova E.Yu. Discursive Personality of the Translator: Translation Competencies and Role Portrait. Vestnik Volgogradskogo gosudarstvennogo universiteta. Seriya 2, Yazykoznanie [Science Journal of Volgograd State University. Linguistics], 2017, vol. 16, no. 3, pp. 90-102. (in Russian). DOI: https://doi.org/10.15688/ jvolsu2.2017.3.9
\end{abstract}

УДК $81 ’ 25: 06.053 .56$

Дата поступления статьи: 17.05.2017

ББК 81.18 Дата принятия статьи: 12.07.2017

\section{ДИСКУРСИВНАЯ ЛИЧНОСТЬ ПЕРЕВОДЧИКА: ПЕРЕВОДЧЕСКИЕ КОМПЕТЕНЦИИ И РОЛЕВОЙ ПОРТРЕТ ${ }^{1}$}

\author{
Элина Юрьевна Новикова \\ Волгоградский государственный университет, г. Волгоград, Российская Федерация
}

\begin{abstract}
Аннотация. В статье характеризуются профессиональные и дискурсивные особенности переводческой деятельности. На основе критического анализа отечественной и зарубежной научной литературы по переводоведению выявлено, что объем понятия «переводческая компетенция», которое трактуется как комплекс способностей, знаний и навыков как результат взаимодействия субъективных и объективных факторов, увеличивается вследствие расширения дискурсивных практик, требующих участия в коммуникации переводчика, и глобализованного развития современного общества. Внимание автора сфокусировано также на рассмотрении различных подходов к определению ролевого статуса переводчика. Раскрыта зависимость процесса формирования дискурсивной личности переводчика, его профессионального портрета и коммуникативного поведения от характера переводческого действия, которое осуществляется в различных коммуникативных условиях. Установлено, что с каждым новым коммуникативным актом переводчик приобретает новые дискурсивные черты и представляет собой сложный мульти- и междискурсионный феномен. Исследование показало, что переводчик, выступая экспертом межкультурной коммуникации, посредником
\end{abstract}


между мирами и культурами, языковым консультантом, специалистом в области другой культуры, соавтором, актером, драматургом, медиатором культур, дизайнером, партнером, наблюдателем и др., является элитарной мультифункциональной социокоммуникативной дискурсивной личностью homo universalis.

Ключевые слова: переводчик, дискурсивная личность, ролевой портрет, профессиональная компетенция, туристический дискурс.

Цитирование. Новикова Э. Ю. Дискурсивная личность переводчика: переводческие компетенции и ролевой портрет // Вестник Волгоградского государственного университета. Серия 2, Языкознание. - 2017. T. 16, № 3. - C. 90-102. - DOI: https://doi.org/10.15688/jvolsu2.2017.3.9

\section{1}

С момента становления переводоведения как отдельной дисциплины, основы которой были заложены Лейпцигской школой перевода, переводчиком, или транслятором, принято считать межкультурного посредника, связующее звено между двумя текстовыми действиями. Однако такое широкое представление нуждается в уточнении, поскольку деятельность профессионального переводчика многогранна: переводческое действие происходит в рамках различных дискурсивных практик, которые по-разному формируют дискурсивную личность переводчика, его профессиональный портрет и коммуникативное поведение.

В рамках статьи рассмотрим некоторые существующие в современном переводоведении подходы к выявлению специфики переводческой компетенции и ролевого имиджа переводчика, в совокупности характеризующие его дискурсивную личность.

\section{2}

Компетентность переводчика - это комплекс способностей, знаний и навыков как результат взаимодействия субъективных и объективных факторов [Митягина, 2016, с. 244]. Наполнение переводческой компетенции представляет собой предмет различных транслатологических исследований и варьируется в различных концепциях. Так, классик отечественного переводоведения В.Н. Комиссаров при характеристике переводческой компетенции выделял в качестве самостоятельных языковую, текстообразующую, коммуникативную, техническую (техника перевода) и личностную компетенции переводчика [Комиссаров, 2002]. К обязательным умениям переводчика он отнес умение переключаться с одного языка на другой, умения предпереводческого характера (интерпретация содержания оригинала, определение стратегии перевода) и проблемнопереводческого характера (поиск средств перевыражения на языке перевода (ПЯ), использование общих переводческих приемов) [Комиссаров, 1997, с. 35-36]. Информационное развитие современного общества и вместе с ним расширение инструментальных технологических возможностей в переводческой професии предопределили необходимость владения переводчиком дополнительными компетенциями, например информационно-технической, которая не получила своего описания в работах В.Н. Комиссарова.

Многокомпонентная классификация составляющих переводческой компетенции представлена в материалах европейского проекта EMT (European Master's in Translation), обеспечивающего с 2007 г. подготовку переводчиков-магистров и предписывающего освоение шести компетенций, которые формируют так называемую метакомпетенцию, необходимую для осуществления профессиональной деятельности переводчиков:

- компетенции оказания переводческих услуг (знать, как вести переговоры с клиентами; следовать требованиям рынка; получать доступ к информации; планировать личное время; работать в команде; соблюдать инструкции, соглашения, профессиональную этику);

- языковой компетенции (знать и уметь применять грамматические, лексические, идиоматические структуры исходного языка и языка перевода с учетом переводческих конвенций);

- культурной компетенции (знать и применять правила поведения и общения в определенном обществе, включая знания невербальных средств коммуникации; знать, как составить документ в соответствии со стандартами, принятыми в культуре языка перевода); 
- поисковой компетенции (умение искать, запрашивать и оценивать необходимую информацию, в том числе в сети Интернет);

- технической компетенции (умение осваивать и использовать программы, облегчающие процесс перевода);

- специальной компетенции (стремление к приобретению специальных знаний в какойлибо сфере деятельности) [Competences...].

Л.К. Латышев и В.И. Провоторов, опираясь на работы и подходы В.И. Комиссарова, наряду с упомянутыми им компетенциями включают в переводческую компетенцию умение целеполагания и предвосхищения результатов перевода, то есть вероятностное прогнозирование [Латышев, Провоторов, 2001, c. 26]. Кроме того, авторы разработали отличную от представленной в работах В.И. Комиссарова структуру переводческой компетенции, выделив базовую, специфическую и спеииальную составляющие. Базовая составляющая включает в себя навыки и умения, необходимые для осуществления всех видов перевода, специфическая - навыки и умения, необходимые в определенном виде устного или письменного перевода, а специальная составляющая - навыки и умения, необходимые при переводе текстов, относящихся к определенной предметной области / речевому жанру [Латышев, Провоторов, 2001, с. 8-9].

Признавая значительный вклад авторов в развитие отечественного переводоведения, предлагаем внести некоторые уточнения в заявленную структуру компетенций. Мотивированным представляется выделение базовых умений переводчика, маркирующих данную профессию, специфических умений, которые применимы к конкретному виду перевода, и специальных, дискурсивно обусловленных, умений. Для письменного и устного видов переводов, равно как для специального и художественного действуют «свои» нормы, правила, требования. Коммуникативное действие переводчика в различных дискурсах - юридическом, медицинском, политическом или туристическом и др. - имеет свои специфические черты. Так, если в медицинском или юридическом дискурсе действуют требования беспристрастности, предельной точности и максимальной близости к оригиналу, то для туристического свойственна креативная свобода переводчика в текстовой деятельности, когда адекватность достигается порождением «неэквивалентного» текста. Таким образом, отметим значимую роль вида перевода и его дискурсивной детерминированности.

Переводческая компетенция с учетом культурно-ситуативного подхода охарактеризована в работах немецких переводоведов. Например, В. Виллс на фоне таких умений переводчика, как восприятие текста, пополнение знаний, анализ исходного текста, синтез информации для порождения текста перевода, оценка результатов перевода, оперативность выполнения перевода, выделяет три основные переводческие компетенции - Kontext, Kultur, Kompensation (контекстная, культурная, компетенция компенсации) [Wilss, 1992]. (Здесь и далее по тексту перевод иноязычных источников наш. - Э. Н.)

Контекстная компетенция. Контекст определяется В. Виллсом двояко:

- заказчик перевода подробно формулирует коммуникативное задание и, таким образом, контекст перевода известен переводчику сразу (объем, вид / тип перевода, оптимальные решения, качество, количество и т. д., например, заказ на перевод специализированной книги заключается в переводе книги в другом жанре для широкой аудитории);

- заказ на перевод не содержит конкретных указаний относительно социокультурных особенностей, получателя, временных установок и других прагматических характеристик. В этом случае переводчик самостоятельно определяет контекст перевода (по W-формуле Г. Лассуэлла) и принимает переводческие решения.

Осознание и понимание контекста является важнейшей предпосылкой гармоничного переводческого действия, поскольку контекст позволяет преодолеть несовпадение картины мира переводчика и картины мира получателя. Контекст позволяет сформировать прагматическую программу заказа и необходимые переводческие стратегии.

Культурная компетенция. Природу и суть переводческого действия можно понять, рассматривая его только в социокультурном измерении вне зависимости от сложности ситуативных коммуникативных рамок. Различия двух лингвокультур не являются причиной не- 
переводимости. Возможный вариант перевода переводчик находит на основе культурного контекста, с которым он работает.

Компетенщия компенсации. Практика перевода имеет многочисленные примеры, когда для достижения содержательной и языковой адекватности в переводе в случае культурных различий и невозможности так называемого прямого языкового трансфера (дословного перевода) применяется прием компенсации. При этом в каждой конкретной коммуникативной ситуации приемы компенсации используются переводчиками как отдельными профессиональными личностями по-разному.

Практический опыт переводчиков подтверждает тот факт, что для принятия переводческого решения отправной точкой выступает контекст, то есть дискурсивно обусловленные условия коммуникации, с одной стороны, и интенции заказчика - с другой. Адекватными переводческие решения можно считать в случае достижения культурной гармонии посредством различных приемов.

Профессиональный переводчик - это эксперт, который осознает специфику коммуникативной ситуации и берет на себя ответственность перед коммуникантами. Немецкий переводовед Х. Риску в своей книге «Translatorische Kompetenz» экспертную компетенцию переводчика определяет как наиболее значимую составляющую в структуре профессиональной компетенции переводчика, который, по ее мнению, должен понимать цели коммуникации, разрабатывать в каждой конкретной ситуации модель коммуникации и действовать в соответствии со своей авторефлексией [Risku, 1998, S. 89]. Экспертная компетенция это социальный феномен компетентности, и она не равна, по Х. Риску, когнитивному феномену понимания предмета коммуникации [Risku, 1998, S. 89]. Эксперт характеризуется как профессиональный переводчик, имеющий специальные знания технологии перевода, принципов, стратегий и тактик перевода. Переводческая компетенция, как полагает $\mathrm{X}$. Риску, формируется на основе когнитивной, коммуникативной и языковой компетенций и дополняется такими компетенциями, как $c a$ моорганизация, планирование коммуникативного поведения и текстопорождения, компетенщия принятия переводческого ре- шения, информащионная компетенция. Следовательно, переводчика можно сравнить с драматургом, который разрабатывает определенный сценарий коммуникации и координирует ее, но не является непосредственным актером, или с туроператором, который полностью организует путешествие, но сам не отправляется в поездку. Экспертное действие переводчика начинается с переводческого заказа, когда становится ясен весь последующий сценарий коммуникации: специфика текста, роли участников, время, место, цели, обстоятельства, стратегии. Переводчик анализирует компоненты дискурсивной матрицы и составляет переводческое досье для последующей межкультурной медиации. Дискурсивное досье коммуникативной ситуации / текста позволяет активизировать мыслительную деятельность переводчика, оптимизировать его коммуникативное действие как культурного транслятора. При этом эффективность культурного трансфера измеряется уровнем сформированности профессиональных компетенций. Набор компетенций по качественным и количественным показателям весьма широк ввиду многогранной дискурсивной деятельности современного переводчика, его многоролевого репертуара.

\section{3}

Сравнение переводчика с драматургом, предложенное X. Риску, в образной форме характеризует ролевые особенности профессиональной экспертной переводческой личности, сформированные на основе различных компетенций. Рассмотрим, как представляют профессиональную личность переводчика другие исследователи.

Антропологический ракурс лингвистики язык - культура - личность направил вектор исследований в сторону языковой личности говорящего в целом и переводчика в частности. Работы, в которых конструируется личность переводчика [Аликина, 2014; Бушев, 2010; Гуреева, 2014; Куницына, 2008; Кушнина, Улитина, 2013; Плотникова, 2008; Пшенкина, 2005; Тарнаева, 2008; Шевченко, 2005; и др.], демонстрируют различные взгляды лингвистов на этот феномен. Они проявляются прежде всего в разнообразии его наимено- 
ваний: коммуникативная личность, языковая личность, дискурсивная личность, сочиокоммуникативная личность, элитарная личность, метаязыковая личность и др.

Социокультурный подход в переводоведении, представленный в публикациях К. Райс и Х. Фермеера, предопределил учет ситуативно обусловленных факторов в работе переводчика и, соответственно, его экспертную позицию в коммуникации. Развивая эти идеи, Р.Л. Ковалевский характеризует переводчика с позиций коммуникативной медиации. Ее рассмотрение в качестве отдельного и многопланового вида посреднической деятельности в различных условиях коммуникации в поликультурном многоязыковом пространстве автор считает оправданным в связи с тем, что ее субъект - медиатор - кроме создания перевода должен решать целый ряд задач поисково-информационного и адаптационного характера [Ковалевский, 2012, с. 71]. Медиатор, по Р.Л. Ковалевскому, - это, с одной стороны, промежуточный «канал связи» между адресантом и адресатом, с другой стороны, адресатпосредник, поскольку он воспринимает и декодирует сообщение адресанта, и адресантпосредник, поскольку перекодирует воспринятый текст и отправляет его непосредственному адресату [Ковалевский, 2012, с. 71].

Трактовка переводческой медиации представлена также в работах Д. Катана, который считал, что переводчик - это «кросскультурный медиатор», синергетическая личность третьего измерения, видимая третья сторона, работающая на стыке культур и подключающая свою ментальность, культурную идентичность, культурный фон для восприятия, интерпретации, конструирования и трансляции метатекстового смысла сообщений инофонной культуры [Katan, 1999, p. 14]. Понимание переводческой медиации, предложенное Д. Катаном, отражает суть переводческой деятельности, так как, по нашему мнению, переводчик не просто посредничает между культурами, он своей межкультурной деятельностью конструирует культуры, способствует их обогащению, регулирует культурные знания и индивидуальную культурную картину участников коммуникации. Как справедливо отмечал X. Фермеер, получатели перевода на языковые ошибки могут не обратить внима- ния, в то время как культурно-специфические не простят [Vermeer, 1989].

Перевод - самый эффективный инструмент формирования культур, культурной идентичности: с одной стороны, так называемой внутренней культурной консолидации, а с другой - внешней культурной дифференциации. Идеальный транслятор-посредник между исходным языком и культурой и целевым языком и культурой является бикультурной личностью [Forstner, 2006, S. 106]. Его задача заключается в посредничестве между культурами и передаче культурных смыслов языка оригинала в язык перевода. Бикультурность при этом понимается не как некое единство культур в сознании их носителя, а как «компетенция между культурами» [Forstner, 2004]. Культурная компетенция транслятора, по мнению 3. Купш-Лозерайт, основывается на множестве компонентов, которые в свою очередь формируют матрицу компетенций [Kupsch-Losereit, 2002, S. 100]. К таким компонентам относятся:

- культурно опосредованные специальные предметные знания;

- коммуникативно-процедуральные знания; - текстовые знания.

Именно культурно опосредованные специальные предметные знания обеспечивают осознанное существование переводчика как минимум в двух культурах. Коммуниканты, социализация которых произошла в их «первичной» культуре, часто реагируют спонтанно, неосознанно, поскольку в этой культуре они чувствуют себя «как дома» и имеют «культурное чутье». Однако в течение всей жизни человек проходит социализацию и инкультурацию, умение коммуницировать в разных контекстах вырабатывается постепенно в определенном культурно-специфическом «круге». При взаимодействии с «чужой» культурой («вторичной») ее особенности воспринимаются и интерпретируются под влиянием своей культуры также неосознанно. Транслятору же неосознанность культурной компетенции не свойственна, так как переводчик всегда осознанно фигурирует в обеих культурах [Löwe, 2002, S. 149]. Немецкий лингвист и переводовед Б. Леве приводит интересные примеры из туристического дискурса о культурно опосредованных знаниях, которыми должен владеть переводчик для адекватного перевода и 
обеспечения коммуникативного эффекта. Прокомментируем два из них:

- во время экскурсии по Новгороду немецикий турист хотел сделать гиду приятное и указал на то, что в городе чувствуется влияние германского Ганзейского периода. Пример иллюстрирует культурные различия в оценке исторической ситуации: для русского человека Новгород имеет исключительно русскую историю, и его процветание в Средневековье поспособствовало тому, что город приобрел мощное влияние в сфере международной торговли и привлек внимание такой организации, как Ганза; для немца же значение города измеряется только наличием связей с западными торговыми структурами [Löwe, 2002, S. 158]. Обладая необходимыми культурными знаниями, переводчик легко справится с прагматической адаптацией вербального контекста коммуникации;

- во время дружеского ужина в ресторане Штутгарта русский гость произнес, что рад побывать не в Штутгарте, а 8 «Четвертом Риме». Различия взглядов немцев и русских на исторические события в случае неадекватного перевода могли бы стать причиной культурно-специфической проблемы в коммуникации. Для России «Третий Рим» (особый статус развития города) - это Москва, что абсолютно неизвестно немцам, и попытка русского гостя сделать комплимент принимающей стороне, подчеркнув величественность европейского города, не произведет должного эффекта.

Коммуникативно-процедуральные знания переводчика подразумевают знания социальных норм, конвенций, жизненного опыта, ценностей, форм общения и т. д. Эти знания накапливаются в ментальном поле переводчика и зависят от многочисленных коммуникативных ситуаций: в ресторане, у врача, в магазине и др., то есть различные дискурсивные социокоммуникативные практики диктуют определенные модели поведения и интеракции.

Текстовые знания являются выражением культурного понимания текста оригинала и способностью создать культурно адекватный текст перевода. Спектр компонентов формируется на макро- и микроуровнях, от морфологии и лексики до оформления, дизайна, невербальных компонентов. Переводческая деятельность - это в том числе текстовая деятельность. Переводчик выступает дизайнером текста, который по формальным конвенциям соответствует оригиналу, а по культурным - адекватен целевой культуре.

Комплексный ролевой портрет переводчика представлен в работах Е.Р. Поршневой, которая выходит за рамки восприятия переводчика как медиатора-посредника и выделяет девять его ролей:

- посредник: обеспечение коммуникации представителей разных культур;

- интерпретатор: интерпретация ситуации общения и поведения участников коммуникации;

- производитель: создание текста на ПЯ;

- nсихолог: недопущение коммуникативных сбоев, корреляция межличностных отношений;

- организатор: организация условий для работы, адаптация к условиям перевода;

- исследователь: сбор и обработка информации по предметной тематике переводческой ситуации;

- aдаптатор: адаптация текста перевода для участников коммуникации;

- корректор: техническое редактирование текста перевода;

- редактор: редактирование текста перевода [Поршнева, 2002, с. 51-52].

В действительности переводчик выполняет множество функций в зависимости от коммуникативной ситуации перевода, поэтому его ролевой репертуар, выявленный Е.Р. Поршневой, представляется логичным и реалистичным. Учитывая тот факт, что палитра навыков и умений переводчика весьма разнообразна, к указанным ролям, безусловно, можно добавлять другие, отражающие важные переводческие умения. Д. Робинсон справедливо утверждает, что переводчики должны иметь актерские способности, обладать даром перевоплощения, совмещать в себе несколько личностей и выполнять различные роли [Робинсон, 2007, с. 28-29]. Эта же мысль встречается у П. Куссмауля, который говорил о необходимости «притворства» в работе переводчика: по его мнению, переводчик должен уметь входить в разные роли, чтобы считаться экспертом [Kussmaul, 1995, p. 33]. Дру- 
гими словами, к портрету переводчика добавляется позиция актер. В определенных ситуациях устного перевода для выполнения конкретных коммуникативных задач переводчик должен повторять интонационный рисунок говорящего, уметь играть голосом, в ряде ситуаций - развлекать в соответствии с переводческим заказом и пожеланиями заказчика перевода. Например, в процессе экскурсионного переводческого обслуживания переводчик иногда рассказывает анекдоты, поет и другими способами развлекает экскурсантов в незадействованное экскурсией время. На практике часто приходится получать переводческий заказ в такой формулировке: «Мне неважно, что Вы будете рассказывать, главное, чтобы гостям было весело, интересно, комфортно и они захотели сюда вернуться».

В переводоведении представлены работы, в которых ролевой портрет переводчика создается с учетом антропологической классификации ролевого статуса говорящего, предложенной Е.В. Падучевой. Так, Т.Г. Пшенкина рассматривает переводчика в качестве наблюдателя, который способен определить вектор и степень смещения в значении знаков, увидеть культурноспецифическое - немаркированное в одной концептуальной системе и маркированное в другой - в том, что ранее воспринималось универсальным, только при «пересечении» языковой и культурной границы снаружи, извне [Пшенкина, 2005, с. 146]. Такой подход представлется оправданным, поскольку аналитическая деятельность является константным компонентом мыслительной деятельности переводчика, так как он постоянно анализирует ситуацию, определяет особенности участников коммуникации, выявляет смыслы, культурные образы, подбирает языковые средства. Для создания гармоничного перевода необходимо занимать позицию наблюдателя, причем как внешнего, то есть формировать свой опыт о внешнем мире, так и внутреннего, то есть осознавать свои переводческие решения, удачи и проблемы.

В публикациях О. Каде находит отражение точка зрения, согласно которой переводчик выполняет три роли:

1) получателя сообщения на исходном языке;
2) перекодирующего звена (промежуточного звена между отправителем и получателем);

3) косвенного отправителя сообщения на переводящем языке [Kade, 1980]. Очевидно, что О. Каде рассматривал вопрос о сопричастности переводчика к коммуникативному акту: переводчик - это партнер по коммуникации, а не отстраненное нейтральное «третье лицо». Он сначала воспринимает исходный текст как самостоятельная личность под влиянием своего мировоззрения, опыта, культуры, далее перевоплощается в «третье лицо» и декодирует, перекодирует и синтезирует сообщение под влиянием культуры языка перевода и прагматики ситуации в целом и наконец транслирует новый текст (текст перевода) на другом языке в роли отправителя. Иными словами, переводчик находится в нескольких коммуникативных пространствах, являясь автором одного из них.

Понятие переводческого пространства мы встречаем в различных исследованиях. Ирландский переводовед М. Кронин в своей книге «Across the Lines. Travel, Language, Translation» сравнивает переводчика с путешественниками и авторами литературы путешествий, так как они всегда в путешествии по языкам и культурам. Иногда они активные участники путешествия, иногда наблюдатели, иногда познают нечто новое, иногда полностью растворяются в «другом» языке и культуре [Cronin, 2000, p. 102-104].

Переводчик М. Кронина - это «переводчик-кочевник», который, путешествуя, что-то берет из одной культуры и привносит что-то в другую или, наоборот, ничего не заимствует. В этом путешествии из своей национальной культуры и мышления в чужую М. Кронин наделяет переводчика собственным отдельным «третьим» ментальным пространством, в котором происходит преобразование родного и иностранного языка, равно как своей и чужой культур под новым углом когнитивного измерения. Это так называемое «межпространство» (entre-deux) содержит множественные культурные идентичности, которыми «жонглирует» переводчик в каждой отдельной ситуации перевода. Это пространство пополняемое, изменяемое, поскольку интерпретируемые смыслы двух разных культур остаются в сознании переводчика, синтезируют- 
ся и трансформируют это сознание, что оказывает влияние на последующее мышление, речь, коммуникативное поведение переводчика. Он, будучи «путешественником» между мирами, языками, культурами, как никто другой, понимает межкультурные различия, причины коммуникативного дискомфорта, сбоя и непонимания и предпринимает различные стратегии по нивелированию межкультурных барьеров.

Инновационный взгляд на переводческое пространство предлагает Л.В. Кушнина. Под переводческим пространством она понимает синергетическую модель перевода, которая объясняет процесс смыслопорождения текста перевода как совокупность множества эксплицитно-имплицитных смыслов, формируемых в сознании переводчика [Кушнина, 2016]. Переводческое пространство, по мнению Л.В. Кушниной, имеет ядро, вокруг которого формируются поля трех субъектов переводческой коммуникации: автора (адресанта), переводчика, реципиента (адресата), - и периферию. Кроме того, образуются еще два текстовых поля, которые Л.В. Кушнина обозначает как энергетическое и фатическое (культурологическое) [Кушнина, 2014, с. 16-17]. В каждом из полей происходит порождение смысла и его вербализация. В результате синергии полей и смыслов создается или в идеальном случае должны быть созданы гармоничный перевод и, соответственно, успешная коммуникация. Описание переводческой деятельности как поля и / или нескольких полей представляется нам вполне обоснованным, так как смыслы, передаваемые в коммуникативной цепи отправитель - переводчик получатель, обретают различное звучание в восприятии и вербализации каждого из участников, ввиду того что участники коммуникации являются отдельными социокоммуникативными и лингвокультурными личностями.

Основной компетенцией переводчика Л.В. Кушнина считает коммуникативную компетенцию. Она формирует коммуникативную личность переводчика, которая, по мнению исследователя, приобретает в ходе успешной переводческой деятельности черты элитарности, создает качественный перевод, столь же уникальный и неповторимый, как и оригинал [Кушнина, 2013, с. 16-18].
В работах других исследователей переводчик характеризуется, прежде всего, в качестве языковой личности. Так, Т.Г. Пшенкина определяет переводчика как «функциональный орган», который отражает способность личности в зависимости от средовых условий проявлять / образовывать новые свойства в процессе своего функционирования для осуществления определенного достижения [Пшенкина, 2005, с. 190-210]. Л.П. Тарнаева считает основными факторами формирования языковой личности и ее профессильнальной деятельности ситуативный контекст межкультурной коммуникации и личностные характеристики переводчика. Специфичность языковой личности Л.П. Тарнаева видит в способности адекватного соотнесения лингвокультурных явлений, эксплицирующих этносоциокультурные характеристики менталитетов, контактирующих в переводческом процессе [Тарнаева, 2008, с. 61].

Развивая идеи многорольности, социоцентричности и поликультурности, Е.В. Аликина называет переводчика метаязыковой личностью, которая, по ее мнению, представляет собой профессиональную языковую личность межкультурного и межъязыкового посредника [Аликина, 2014]. Он является личностью, создающей универсальное мыслительное пространство, аккумулирующее мысли других языковых личностей; сбалансированным билингвом; носителем элитарной речевой культуры; профессионалом, выстраивающим свое речевое и невербальное поведение в соответствии со стратегиями, обеспечивающими максимально положительный коммуникативный эффект, и осознанием возможных рисков, а также в пределах профессиональных этикодеонтологических норм [Аликина, 2014].

Если в работах Е.В. Аликиной акцент делается, скорее, на когнитивных компонентах личности переводчика, то в диссертационном исследовании А.А. Гуреевой «Социокоммуникативные характеристики языковой личности переводчика (на материале русского и английского языков)» переводчик представлен как профессиональная транслатологическая личность, формирующаяся в результате интеграции первичной и вторичной языковых личностей под воздействием требований профессиональной ситуации. Как пер- 
вичная языковая личность, сформированная на родном языке, переводчик соотносится с элитарной личностью: он владеет нормами литературного языка, этическими и коммуникативными нормами, способен создавать тексты, соответствующие ситуации и целям общения, имеет богатый активный и пассивный словарный запас [Гуреева, 2014, с. 6]. В данной трактовке очевиден приоритет ситуативного контекста в работе переводчика, его социабельность и коммуникативность.

Разделяя идеи социабельности переводчика и ситуативности его действия, мы склонны полагать, что переводчик - личность дискурсивная, поскольку существует и реализуется только в конкретных дискурсах: профессиональном переводческом, дипломатическом, юридическом, экономическом, туристическом и др. Между дискурсом и личностью в контексте социокоммуникативного подхода наблюдается взаимозависимость: с одной стороны, личность как обобщенный образ представителя национальной культуры формирует дискурс, а с другой - дискурс является средством самовыражения личности. Это утверждение в полной мере относится к переводчику, который формирует межкультурный межъязыковой дискурс и самовыражается в нем как автор / соавтор культурно обусловленных ментальных пространств. Очевидно, что переводчик, реализуя коммуникативное действие в различных дискурсах, приобретает с каждым коммуникативным актом новые дискурсивные черты и, таким образом, представляет собой сложный мульти- и междискурсивный феномен. Социокультурная прагматика коммуникативного действия переводчика зависит от множества факторов институционального дискурсивного контекста.

Переводчик является активным сотворцзом мыслительного ландшафта, мира текста и культур. Границы свободы переводческой деятельности и способность избежать хаоса в «сотворении» картины мира в сознании коммуникантов Э. Прунч видит в ответственности переводчика, заложенной в профессиональной этике, в культуре перевода, которая понимается как сформированная, самоконтролируемая система культуры переводческой деятельности, сложившейся под влиянием социокультурных норм, конвенций, ожиданий, ценностей, моделей поведения всех задействованных в коммуникации участников [Prunč, 1997; 2000; 2003]. Другими словами, культура перевода и есть профессионализм переводчика.

Современные условия глобализации и интенсивные миграционные процессы предъявляют к переводчику требование реализации консалтинговой функции в некоторых коммуникативных контекстах. Это касается, прежде всего, индустрии интернет-локализации и социального перевода (Community Interpreting). Дуализм отношений переводчик - текст постепенно, с развитием мультимедиальных технологий и информационных средств в работе переводчика (CAT Translation), а также появлением новых профессиональных профилей межкультурных экспертов (например, технический писатель), превращается в командную работу в направлении меж- и транскультурного менеджмента.

Австрийский переводовед, специалист в области локализации П. Сандрини считает, что переводчик в процессе локализации вебсайта выступает в роли советника-консультанта клиента (заказчика), работая с ним сообща при создании иноязычной версии ресурса. Так, совместно анализируется содержание контента, включая степень локализации, количество языковых версий и т. д. [Sandrini, 2005, S. 217-218]. В задачи переводчика входит адаптация стратегий перевода и локализации к другим проектам заказчика: унификация терминологии, создание при необходимости рекламного текста на веб-странице, кооперация с другими сотрудниками по проекту и редактирование перевода. Командная работа по локализации сайта, очевидно, наделяет переводчика новыми компетенциями и функциями. Он не является конечным звеном цепи проекта по локализации и не только переводит отдельные тексты в рамках переводческого заказа, но и благодаря своим профессиональным транслатологическим и культурным знаниям и умениям выступает активным участником процесса и имеет большое влияние на создание всего многоязычного контента. Из этого можно заключить, что индустрия локализованных продуктов кардинальным образом расширила рамки переводческой деятельности от простого транскодирования языковых знаков до многоформатной 
кооперативной профессиональной личности полноценного участника коммуникативного процесса и дискурса в целом.

\section{4}

Обращение к классическим и современным работам по переводоведению на предмет выявления роли переводчика и специфики его профессиональной деятельности позволило найти новую грань в изучении данного феномена, а именно дискурсивный подход. Дискурсивно обусловленная детельность переводчика послужит толчком для дальнейших исследований его места и роли в коммуникативных пространствах различных дискурсов.

Профессиональный переводчик, который выступает экспертом межкультурной коммуникации, посредником между мирами и культурами, языковым консультантом, специалистом в области другой культуры, соавтором, актером, драматургом, медиатором культур, дизайнером, партнером, наблюдателем, кочевником, то есть элитарным homo universalis, может быть охарактеризован как мультифункциональная социокоммуникативная дискурсивная личность, агент дискурса, обладающий широким набором компетенций.

\section{ПРИМЕЧАНИЕ}

${ }^{1}$ Исследование выполнено при финансовой поддержке Российского фонда фундаментальных исследований (РФФИ) и Администрации Волгоградской области, проект № 17-14-34001 «Региональный туризм как фактор формирования дискурса и технологии перевода: номинативные и коммуникативно-прагматические конвенции текстов брендинга» (Региональный конкурс «Волжские земли в истории и культуре России» 2017 - Волгоградская область).

\section{СПИСОК ЛИТЕРАТУРЫ}

Аликина, Е. В. Переводчик как метаязыковая личность / Е. В. Аликина / Филологические науки. Вопросы теории и практики. - 2014. - №4 (34), ч. 1. C. 15-18.

Бушев, А. Б. Русская языковая личность профессионального переводчика : автореф. дис. ... д-ра филол. наук / Бушев Александр Борисович. - М., 2010. $-47 \mathrm{c}$.
Гуреева, А. А. Социокоммуникативные характеристики языковой личности переводчика (на материале русского и английского языков) : автореф. дис. ... канд. филол. наук / Гуреева Анна Андреевна. - Волгоград, 2014. - 18 с.

Ковалевский, Р. Л. Перевод versus коммуникативная медиация / Р. Л. Ковалевский // Подготовка переводчика: коммуникативные и дидактические аспекты : коллектив. моногр. / науч. ред. В. А. Митягина. - М. : ФЛИНТА : Наука, 2012. - С. 66-86.

Комиссаров, В. Н. Современное переводоведение / В. Н. Комиссаров. - М. : ЭТС, 2002. - 326 с.

Комиссаров, В. Н. Теоретические основы методики обучения переводу / В. Н. Комиссаров. М. : Рема, 1997. - 153 с.

Куницына, Е. Ю. Языковая личность переводчика как сущность и ипостась / Е. Ю. Куницына // Известия Волгоградского государственного педагогического университета. - 2008. - № 10 (34). С. 103-106.

Кушнина Л. В. От коммуникативных компетенций - к коммуникативной личности переводчика / Л. В. Кушнина, С. Г. Улитина // Известия Волгоградского государственного педагогического университета. - 2013. - № 9(84). - С. 16-18.

Кушнина, Л. В. Переводческое пространство как стратегия межъязыкового и межкультурного взаимодействия / Л. В. Кушнина // Лингвокультурный компонент в переводческом пространстве : коллектив. моногр. / Отв. ред. Э. М. Рянская. - Нижневартовск : Изд-во Нижневарт. гос. ун-та, 2014. C. 4-38

Кушнина, Л. В. Языковая личность профессионального переводчика: когнитивный аспект / Л. В. Кушнина // Вестник Челябинского государственного университета. - 2016. - № 4 (386). Филологические науки. Вып. 100. - С. 85-88.

Латышев, Л. К. Структура и содержание подготовки переводчиков в языковом вузе / Л. К. Латышев, В. И. Провоторов. - М. : НВИ - ТЕЗАУРУС, 2001. $-136 \mathrm{c}$.

Митягина, В. А. Рефлексии переводчиков как основа оптимизации профессиональных компетенций / В. А. Митягина // Переводчик XXI века-агент дискурса : коллектив. моногр. / науч. ред. В. А. Митягина, А. А. Гуреева. - М. : ФЛИНТА : Наука, 2016. C. 240-255.

Плотникова, С. Н. Говорящий / пишущий как языковая, коммуникативная и дискурсивная личность / С. Н. Плотникова // Вестник Нижневартовского государственного гуманитарного университета. - 2008. - № 4. - C. 37-42.

Поршнева, Е. Р. Базовая лингвистическая подготовка переводчика / Е. Р. Поршнева. - Нижний Новгород : Изд-во ННГУ им. Н. И. Лобачевского, 2002. $-148 \mathrm{c}$. 
Пшенкина, Т. Г. Вербальная посредническая деятельность переводчика в межкультурной коммуникации: психолингвистический аспект : дис. ... д-ра филол. наук / Пшенкина Татьяна Геннадьевна. - Барнаул, 2005. - 330 с.

Робинсон, Д. Как стать переводчиком: введение в теорию и практику перевода / Д. Робинсон. СПб. : КУДИЦ-ПРЕСС, 2007. - 304 с.

Тарнаева, Л. П. Концепция языковой личности в контексте проблем переводоведения / Л. П. Тарнаева // Вестник Ленинградского государственного университета им. А.С. Пушкина. Серия «Филология». - 2008. - № 2 (13). - С. 55-68.

Шевченко, О. Н. Языковая личность переводчика: на материале дискурса Б.В. Заходера : автореф. дис. ... канд. филол. наук / Шевченко Ольга Николаевна. - Волгоград, 2005. - 22 с.

Competences for professional translators, experts in multilingual and multimediacommunication. EMT expertgroup. - Electronic text data. - Mode of access: http://ec.europa.eu/dgs/translation/programmes/ emt/ key_documents/emt_competences_translators_en. pdf. - Title from screen.

Cronin, M. Across the Lines. Travel, Language, Translation / M. Cronin. - Cork : Cork University Press, 2000. -172 p.

Forstner, M. Der Übersetzer zwischen Kulturen / M. Forstner // CIUTI-Forum Paris 2005. regards sur les aspects culturels de la communication / M. Forstner, H. LeeJahnke(Hg.). - Bern : Peter Lang, 2006. - S. 87-117.

Forstner, M. Translation als Aufgabe / M. Forstner // Internationales CIUTI- Forum. Marktorientierte Translationsausbildung / M. Forstner, H. Lee-Jahnke (Hg.). - Bern : Peter Lang, 2004. - S. 11-58.

Kade, O. Die Sprachmittlung als gesellschaftliche Erscheinung und Gegenstand wissenschaftlicher Untersuchung/O. Kade//Ubersetzungswissenschaftliche Beihefte,H., III. - Leipzig: VEBEnzyklopädie, 1980.-285 S.

Katan, D. Translating Cultures / D. Katan. Manchester : St. Jerome Publishing, 1999. - 271 p.

Kupsch-Losereit, S. Die Kulturelle Kometenz des Translators / S. Kupsch-Losereit // Lebende Sprachen. - 2002. -47/3. - S. 97-101.

Kussmaul, P. Training the Translator / P. Kussmaul. - Amsterdam and Philadelphia : John Benjamins, 1995. -177 p.

Löwe, B. Translatorische Kulturkompetenz: InhalteErwerb- besonderheiten / B. Löwe // Übersetzen und Dolmetschen / J. Best, S. Kalina (Hg.). - Tübingen; Basel : Francke, 2002.-S. 148-162.

Prunč, E. Óptimo, subóptimo, fatal: refelexiones sobre la democracia etnolingüística en la cultura europea de traducción / E. Prunč // La direcconalidad en traducción e interpretación: perspectivas teóreticas, profesionales y didácticas / D. Kelly, A. Martin, M.-L. Nobs [et al.] (eds.). -Granada : Atrio, 2003. - S. 67-89.
Prunč, E. Translationskultur. Versuch einer konstruktiven Kritik des translatorischen Handelns / E. Prunc // TEXTconTEXT, 11 = NF (Neue Folge). 1997. - Vol. 1. - S. 99-126.

Prunč, E. Vom Translationsbiedermeier zur Cybertranslation / E. Prunč // TextConText, 14, NF (Neue Folge). - 2000. - Vol. 4. - S. 3-74.

Risku, H. Translatorische Kompetenz Kognitive Grundlagen des Übersetzens als Expertentätigkeit / H. Risku. - Tübingen : Stauffenberg-Verlag, 1998. Bd. 5. $-286 \mathrm{~S}$.

Sandrini, P. Translationstechnologie. Überblick und Aussicht / P. Sandrini // Translatologie - Neue Ideen und Ansätze. Innsbrucker Ringvorlesungen zur Translationswissenschaft IV / L. Zybatow (Hg.). Frankfurt: Lang, 2005. - S. 203-220.

Vermeer, H. Kulturspezifik des translatorischen Handels / H. Vermeer. - Heidelberg : Universitätsdrpckerei Heidelberg, 1989. - S. 84-111.

Wilss, W. Übersetzungsfertigkeit. Annäherung an einen komplexen übersetzungspraktischen Begriff / W. Wilss. - Tübingen : Narr, 1992. - 376 S.

\section{REFERENCES}

Alikina E.V. Perevodchik kak metayazykovaya lichnost [Translator as a Metalinguistic Personality]. Filologicheskie nauki. Voprosy teorii i praktiki [Philological Sciences. Issues of Theory and Practice], 2014, no. 4(34), part 1, pp. 15-18.

Bushev A.B. Russkaya yazykovaya lichnost professionalnogo perevodchika: avtoref. dis. ...d-ra filol. nauk [Russian Language Personality of the Professional Translator. Dr. philol. sci. abs. diss.]. Moscow, 2010. 47 p.

Gureeva A.A. Sotsiokommunikativnye kharakteristiki yazykovoy lichnosti perevodchika (na materiale russkogo i angliyskogo yazykov): avtoref. dis. ... kand. filol. nauk [Social and Communicative Features of an Interpreter's Personality. Cand. philol. sci. abs. diss.]. Volgograd 2014. 18 p.

Kovalevskiy R.L. Perevod versus kommunikativnaya mediatsiya [Translation versus Communicative Mediation]. Mityagina V.A., ed. Podgotovka perevodchika: kommunikativnye $i$ didakticheskie aspekty: koll. monografiya [Training of an Interpreter: Communicative and Didactic Aspects: Collective Monograph]. Moscow, FLINTA, Nauka Publ., 2012, pp. 66-86.

Komissarov V.N. Sovremennoe perevodovedenie [Modern Translation Studies]. Moscow, ETS Publ., 2002.326 p.

Komissarov V.N. Teoreticheskie osnovy metodiki obucheniya perevodu [Theoretical Bases of 
Translation Teaching]. Moscow, Rema Publ., 1997. $153 \mathrm{p}$.

Kunitsyna E.Yu. Yazykovaya lichnost perevodchika kak sushchnost i ipostas [Linguistic Personality of the Professional Translator as an Essence and Guise]. Izvestiya Volgogradskogo gosudarstvennogo pedagogicheskogo universiteta, 2008, no. 10 (34), pp. 103-106.

Kushnina L.V., Ulitina S.G. Ot kommunikativnykh kompetentsiy-k kommunikativnoy lichnosti perevodchika [From the Communicative Competence to the Translator's Linguistic Identity]. Izvestiya Volgogradskogo gosudarstvennogo pedagogicheskogo universiteta [Izvestia of the Volgograd State Pedagogical University], 2013, no. 9(84), pp. 16-18.

Kushnina L.V. Perevodcheskoe prostranstvo kak strategiya mezhyazykovogo i mezhkulturnogo vzaimodeystviya [Translation Space as a Strategy of Translanguage and Transcultural Interaction]. Ryanskaya E.M., ed. Lingvokulturnyy komponent $v$ perevodcheskom prostranstve: Kollektivnaja monografija [Linguacultural Component in the Translation Space: Collective Monograph]. Nizhnevartovsk, Izd-vo Nizhnevart. gos. un-ta, 2014, pp. 4-38.

Kushnina L.V. Yazykovaya lichnost professionalnogo perevodchika: kognitivnyy aspekt [Professional Translator's Linguistic Identity: Cognitive Aspect]. Vestnik Chelyabinskogo gosudarstvennogo universiteta [Chelyabinsk State University Bulletin], 2016, no. 4 (386): Philological Sciences, iss. 100, pp. 85-88.

Latyshev L.K., Provotorov V.I. Struktura $i$ soderzhanie podgotovki perevodchikov v yazykovom vuze [Structure and Content of the Translation Studies in Higher School]. Moscow, NVI - TEZAURUS Publ., 2001. 136 p.

Mityagina V.A. Refleksii perevodchikov kak osnova optimizatsii professionalnykh kompetentsiy [Translators' Reflections as a Base of the Professional Competence]. Mityagina V.A., Gureeva A.A., eds. Perevodchik XXI veka - agent diskursa: koll. monografiya [Translator of the $21^{\text {st }}$ Century - a Discourse Agent: Collective Monograph]. Moscow, FLINTA, Nauka Publ., 2016, pp. 240-255.

Plotnikova S.N. Govoryashchiy/ pishushchiy kak yazykovaya, kommunikativnaya i diskursivnaya lichnost [The Speaking / Writing as a Language, Discource, Communicative Personality]. Vestnik Nizhnevartovskogo gosudarstvennogo gumanitarnogo universiteta [Bulletin of Nizhnevartovsk State University], 2008, no. 4, pp. 37-42.

Porshneva E.R. Bazovaya lingvisticheskaya podgotovka perevodchika [Basic Language Training of the Translator]. Nizhniy Novgorod, Izd-vo NNGU im. N.I. Lobachevskogo, 2002. 148 p.
Pshenkina T.G. Verbalnaya posrednicheskaya deyatelnost perevodchika $v$ mezhkulturnoy kommunikatsii: psikholingvisticheskiy aspekt: dis. ... d-ra filol. nauk [Translator's Verbal Mediating in the Cross-Cultural Communication: Psycholinguistic Aspect. Dr. philol. sci. diss.]. Barnaul, 2005. 330 p.

Robinson D. Kak stat perevodchikom: vvedenie $v$ teoriyu i praktiku perevoda [How to Be a Translator: Introduction to Translation Theory and Practice]. Saint Petersburg, KUDIC-PRESS, 2007. 304 p.

Tarnaeva L.P. Kontseptsiya yazykovoy lichnosti $\mathrm{v}$ kontekste problem perevodovedeniya [Linguistic Personality as One of the Translation Problems]. Vestnik Leningradskogo gosudarstvennogo universiteta im. A.S. Pushkina. Seriya «Filologiya» [Vestnik of Pushkin Leningrad State University. Series. Philology], 2008, no. 2 (13), pp. 55-68.

Shevchenko O.N. Yazykovaya lichnost perevodchika: na materiale diskursa B.V. Zakhodera: avtoref. dis. ... kand. filol. nauk [Translator's Linguistic Personality: a Case Study of B.V. Zakhoder's Discource. Cand. philol. sci. abs. diss.]. Volgograd, 2005. 22 p.

Competences for professional translators, experts in multilingual and multimediacommunication. EMT expertgroup. URL: http://ec.europa.eu/dgs/translation/ programmes/emt/key_documents/emt_competences_ translators_en.pdf

Cronin M. Across the Lines. Travel, Language, Translation. Cork, Cork University Press. 2000. 172 p.

Forstner M. Der Übersetzer zwischen Kulturen [The Translator between Cultures]. CIUTI-Forum Paris 2005. regards sur les aspects culturels de la communication [CIUTI-Forum Paris 2005. A Look at the Cultural Aspects of Communication]. Bern, Peter Lang, 2006, pp. 87-117.

Forstner M. Translation als Aufgabe [Translation as a Task]. Internationales CIUTI-Forum. Marktorientierte Translationsausbildung [International CIUTI Forum. Market-Oriented Translation Training]. Bern, Peter Lang, 2004, pp. 11-58.

Kade O. Die Sprachmittlung als gesellschaftliche Erscheinung und Gegenstand wissenschaftlicher Untersuchung [Linguistic Determination as a Social Phenomenon and Object of Scientific Inquiry]. Ubersetzungswissenschaftliche Beihefte, H., III [Translation of Scientific Documents]. Leipzig, VEB Enzyklopädie, 1980. 285 p.

Katan D. Translating Cultures. Manchester, St. Jerome Publishing, 1999. 271 p.

Kupsch-Losereit S. Die Kulturelle Kometenz des Translators [The Cultural Competence of the Translator]. Lebende Sprachen [Living Languages], 2002, 47/3, pp. 97-101.

Kussmaul P. Training the Translator. Amsterdam and Philadelphia, John Benjamins, 1995. 177 p. 


\section{ГЛАВНАЯ ТЕМА НОМЕРА}

Löwe B. Translatorische Kulturkompetenz: Inhalte-Erwerb- besonderheiten [Translational Cultural Competence: Content-Acquisition Features]. Best Joanna, Kalina Sylvia (Hg.) Übersetzen und Dolmetschen [Translating and Interpreting]. Tübingen/Basel, Francke, 2002, pp. 148-162.

Prunč E. Óptimo, subóptimo, fatal: refelexiones sobre la democracia etnolingüística en la cultura europea de traducción [Optimum, Suboptimal, Fatal: Reflections on Ethnolinguistic Democracy in the European Translation Culture]. Kelly Dorothy; Martin Anne; Nobs Marie-Louise et al. (Eds.) La direcconalidad en traducción e interpretación: perspectivas teóreticas, profesionales y didácticas [The Directionality in Translation and Interpretation: Theoretical, Professional and Didactic Perspectives]. Granada, Atrio, 2003, pp. 67-89.

Prunč E. Translationskultur [Translating Culture]. TextConText 11 = NF (Neue Folge), 1997, vol. 1, pp. 99-126.

Prunč E. Vom Translationsbiedermeier zur Cybertranslation [From Translational Flexion to
Cybertranslation]. TextConText $14=N F$ (Neue Folge), 2000, vol. 4, pp. 3-74.

Risku H. Translatorische Kompetenz. Kognitive Grundlagen des Übersetzens als Expertentätigkeit [Translation Competence. Cognitive Fundamentals of Translation as an Expert Activity]. Band 5. Tübingen, Stauffenberg-Verlag, 1998. 286 p.

Sandrini P. Translationstechnologie. Überblick und Aussicht [Translation Technology. Overview and Views]. Zybatow L. (Hg.). Translatologie - Neue Ideen und Ansätze. Innsbrucker Ringvorlesungen zur Translationswissenschaft IV [Translatology-New Ideas and Approaches. Innsbrucker Lectures on Translational Science IV]. Frankfurt, Lang, 2005, pp. 203-220.

Vermeer H. Kulturspezifik des translatorischen Handels [Cultural Specificity of Translatory Trade]. Heidelberg, Universitätsdrpckerei Heidelberg, 1989, pp. 84-111.

Wilss W. Übersetzungsfertigkeit. Annäherung an einen komplexen übersetzungspraktischen Begriff [Translation Skill. Approach to a Complex TranslationPractical Term]. Tübingen, Narr, 1992.376 p.

\section{Information about the Author}

Elina Yu. Novikova, Candidate of Sciences (Philology), Associate Professor, Department of Translation Theory and Practice, Volgograd State University, Prosp. Universitetsky, 100, 400062 Volgograd, Russian Federation, tipp@volsu.ru, nov-elina@volsu.ru, http://orcid.org/0000-0003-4442-9071

\section{Информация об авторе}

Элина Юрьевна Новикова, кандидат филологических наук, доцент кафедры теории и практики перевода, Волгоградский государственный университет, просп. Университетский, 100, 400062 г. Волгоград, Российская Федерация, tipp@volsu.ru, nov-elina@volsu.ru, http://orcid.org/00000003-4442-9071 